\title{
The Effects of a Rehabilitation Exercise Program After Posterior Cruciate Ligament (PCL) Reconstruction Between Genders
}

\author{
Hyun-mok Kim ${ }^{1}$, Chang-kook Kim" ${ }^{*}$, Jung-wook Lee ${ }^{2}$, Sung-hwan Lee ${ }^{1}$ \\ ${ }^{1}$ Department of Sport Convergence, Korea University, Sejong, Republic of Korea \\ ${ }^{2}$ Department of Sports Science Convergence, Dongguk University, Seoul, Republic of Korea
}

Received: August 30, 2021

Accepted: October 29, 2021

Published online: January 31, 2022

Keywords:

$\mathrm{PCL}$

Posterior Cruciate Ligament Rehabilitation

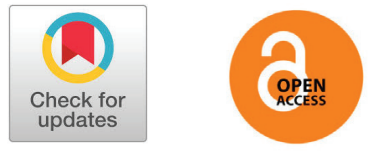

\section{ABSTRACT}

OBJECTIVES The purpose of this study was to examine the effects of a rehabilitation exercise program after posterior cruciate ligament $(\mathrm{PCL})$ reconstruction between genders.

METHODS The research subjects were 22 patients who had posterior cruciate ligament reconstruction. They were divided into Male Group ( $n=11)$ and Female Group $(n=11)$. The dependent variable was Lysholm knee score, IKDC (International Knee Document Committee) score, isokinetic muscle strength of knee joint, which it was measured Pre-Op (Previous Operation) and during the 24-week rehabilitation exercise program period, it was measured at Post-Op (Post Operation) 12 and Post-Op 24 weeks.

RESULTS First, significant differences by period were noted on Lysholm knee score $(p<.001)$ and IKDC score $(p<.05)$. Second, isokinetic strength of knee joint extension in involved side is significant differences between genders $(p<.01)$. Third, isokinetic strength of knee joint extension in involved side has significant differences by period $(p<.01)$. Forth, isokinetic strength of knee joint extension in uninvolved side has significant differences between genders $(p<.05)$. Fifth, isokinetic strength of knee joint flexion in uninvolved side has significant differences between genders $(p<.01)$. Sixth, isokinetic strength of knee joint flexion in uninvolved side has significant differences by period $(p<.05)$.

CONCLUSIONS This paper confirmed that the effect of a rehabilitation exercise program on subjective function is not influenced by gender, but by period. On the other hand, the effect of a rehabilitation exercise program on strength is influenced by not only gender, but also period. That application of rehabilitation exercise program after posterior cruciate ligament reconstruction was significant difference between groups in male and female on isokinetic strength of knee joint and by period. Therefore, we suggest that a rehabilitation exercise program should be designed differently in proper way between male and female group.

(-) The Asian Society of Kinesiology and the Korean Academy of Kinesiology

\section{서론}

후방십자인대 손상은 교통사고나 스포츠 손상, 산업 현장 손상 등 원인이 다양하며 급성 무릎 손상 중 후방

*Correspondence: Chang-kook kim, Department of Sport Convergence, Korea University, 2511 Sejong-ro, Sejong-si, Republic of Korea; Tel: +82-44-860-1361; E-mail: kimck@korea.ac.kr
십자인대 손상율은 전체 급성 인대 손상의 1 44\%로 매 우 다양하게 보고하고 있다[1-4]. 후방십자인대는 슬 관절 안정성에 꼭 필요한 정적 구조물로써 대퇴에 대하 여 경골이 후방으로 과도하게 밀리는 것을 억제하는 중 요한 역할을 한다[5-7]. 이러한 후방십자인대는 손상 후 적절한 치료 및 재활을 받지 않은 채 방치할 경우 골 관절염의 위험요인으로 작용하며 무릎전치환술이 필요 
할 수도 있다[8]. 후방십자인대 재건술 후 재활운동 프 로그램에 관하여 초기 3 주 동안 관절 가동 범위를 고정 하고 6 주 동안 체중 지지를 완전히 제한하는 지연된 재 활운동 프로토콜을 제시하였다[9]. 그러나 무릎의 통증 과 경직을 호소하는 단점이 나타났고, 최근에는 6주 동 안 수동적 관절 가동 범위를 허용하고 무를 완전 신전 상태에서 부분 체중 부하를 허용하는 상호 활동적 재활 운동 프로토콜이 제시되고 있다[10].

한편, 후방십자인대 관절경적 재건술 후 기능 회복을 평가하여 비교한 연구에서는 방사선학적 검사, 주관적 검사, $\mathrm{KT}-2000$ 슬관절 인대 이완 검사 등을 도구로 측 정되었다[11]. 선행 연구에서는 후방십자인대 재건술 후 안정성이 성별에 따라 차이가 나타나는 지에 관하여 주관적 설문지 검사와 방사선 인대 스트레스 검사를 통 해 측정하였다[12]. 재활운동 프로그램의 효과와 관련 하여 후방십자인대 손상 후 재활운동 프로그램 참여가 통증 정도, 관절가동범위 및 근 관절 기능에 미치는 효 과를 측정한 선행 연구 [13]가 있으나, 후방십자인대 재 건술을 시행하지 않은 환자를 대상으로 실시한 연구였 다. 후방십자인대 재건술 후 재활운동 프로그램의 효과 를 평가한 선행 연구들은 다수 존재 하나[14-15], 후방 십자인대 재건술 후 재활운동 프로그램의 효과가 성별 에 따라 차이가 나타나는지에 관한 연구는 부족한 실정 이며 후방십자인대 재건술 후 재활운동 프로그램에 따 른 근력과 주관적 기능에 있어 시기별, 성별 간의 차이 를 면밀하게 분석할 필요가 있다.

이에 본 연구는 후방십자인대 재건술 후 실시한 재활 운동 프로그램이 기능 회복에 미치는 영향이 성별 간 유 의한 수준의 차이가 있는지 확인하고자 하며, 특히 기능 회복을 측정함에 있어 주관적 기능과 근력 기능 2 가지 수준으로 살펴보고자 한다. 이는 후방십자인대 재건술 을 실시한 환자에게 실시한 재활운동 프로그램의 시기 별 효과를 확인하기 위함이며, 환자가 주관적으로 느끼 는 기능 회복과 근력 간의 상관관계가 있는 지를 확인 하고 성별 간 차이를 비교하여 적절한 재활운동 프로그 램을 제안하고자 한다.

\section{연구방법}

\section{1. 연구대상}

본 연구의 참여자는 경기도 소재 $\mathrm{M}$ 종합병원에서 동 일한 정형외과 전문의에게 2 년 이내에 수술 받은 환자
총 22 명을 대상으로 하였다. 성별 집단의 차이를 명확 히 규명하고자 남성과 여성의 성별 구성 비율은 동일하 게 조정하여, 남성 11 명과 여성 11 명으로 구성하였다. 모든 참여자들은 사전에 운동 검사 및 재활운동 프로그 램에 관한 내용을 숙지하고 자발적으로 동의서에 서명 하였다. 참여자의 안전을 위하여 모든 실험의 구성은 임 상 전문의의 지도하에 병원 내에서 실시하였으며, 실험 중 지속적인 통증을 호소하는 인원이 발생할 경우 대상 에서 제외하도록 하였다. 참여자의 신체적 특성은 다음 <Table 1 >과 같다.

Table 1. General characteristics of subjects

\begin{tabular}{llll}
\hline Group & Age (years) & Height $(\mathbf{c m})$ & Weight $(\mathbf{k g})$ \\
\hline Male $(\mathrm{n}=11)$ & $32.46 \pm 10.71$ & $172.54 \pm 5.42$ & $78.36 \pm 11.69$ \\
Female $(\mathrm{n}=11)$ & $35.73 \pm 14.68$ & $161.82 \pm 6.65$ & $59.77 \pm 5.45$ \\
\hline
\end{tabular}

\section{2. 측정 항목 및 방법}

본 연구에서는 주관적 기능과 근력을 측정하기 위해 선행 연구에 근거하여 측정 항목을 설정하였다.

\section{1) 주관적 기능}

Lysholm 무릎 점수는 간단하고 쉽게 환자의 증상과 활동 수준을 측정할 수 있고, IKDC 점수는 슬관절의 다 양한 요소를 측정하고 비교 할 수 있는 점을 고려하여 다음의 두가지 설문지를 주관적 기능 측정을 위한 항목 으로 설정하였다[16].

\section{(1) Lysholm 무릎 점수 (Lysholm knee score)}

Lysholm 무릎 점수는 환자의 기능을 항목별로 나누 어 주관적 판단을 기준으로 점수를 기록한 후, 이를 합 산하여 환자의 슬관절 상태를 평가하는 방법이다. 100 점 만점을 기준으로 점수가 높을수록 상태가 양호한 것 이며, 임상에서 보편화된 검사 방법일 뿐만 아니라 슬 관절 기능 관련 연구에서도 널리 이용되고 있다[16].

\section{(2) IKDC 점수 (International Knee Document} Committee score)

$\mathrm{IKDC}$ 점수는 주관적 점수를 증상, 스포츠 활동, 기 능적 능력으로 나누어 측정하며 100점 만점을 기준으로 점수가 높을수록 상태가 양호한 것으로 판단할 수 있는 방법이다. 무릎과 관련된 포괄적이며 다양한 측면을 평 가할 수 있으며 슬관절 기능 관련 연구에서도 널리 이 용되고 있다[16]. 


\section{(3) 근력}

근력을 측정하기 위하여 Biodex System III isokinetic dynamometer (Biodex Medical System, Shirley-NY, USA) 를 활용하였다. 검사는 슬관절의 신 전력과 굴곡력을 등속성 모드를 사용하여 측정하였다. 등속성 모드는 미리 설정된 속도에서 발휘된 근육의 힘 과 동일한 저항이 가변적으로 적용된다는 장점이 있어 다양한 속도의 기능적 움직임을 정확히 평가할 수 있고 근육이나 인대 손상 환자의 안전한 재활에 활용되고 있 다[17]. 측정을 위해 앉은 자세에서 대퇴골 외측상과를 근력 장비의 동력계 운동 축에 일치시키고 검사하고자 하는 다리의 대퇴부를 밸크로 스트랩으로 단단히 고정 하였다. 세트 간에는 60 초의 휴식 시간이 주어지도록 하 였으며 검사 시 슬관절의 운동 범위는 $0^{\circ}$ 에서 $90^{\circ}$ 로 제 한하여 검사 중 손상이 발생하지 않도록 하였다. 후방 십자인대 손상 및 재건술을 시행하지 않은 건측을 먼저 검사하고 그 이후에 후방십자인대 재건술을 시행한 환 측을 검사하였다. 선행 연구를 바탕으로 대퇴 근력 평 가를 위하여 각속도 $60 \% \mathrm{sec}$ 에서 4 회의 연습 후 4 회 측 정을 실시하였다[17]. 신전 시와 굴곡 시에 최대 우력 (peak torque) 값을 측정하여 체중 당 최대 우력(peak torque/body weight) 값을 백분율(\%)로 조사하였다.

\section{3. 재활운동 프로그램}

본 연구에 사용된 재활운동 프로그램은 Senese 등 이 제안한 후방십자인대 재건술 후 상호 활동적 재활운 동 프로토콜 연구[10]를 바탕으로 <Table 2>와 같은 내용의 상호 활동적 재활운동 프로그램을 별도로 설계 하여 경기도 소재 $\mathrm{M}$ 병원에서 시행하였다. 본 연구에서 사용된 재활운동 프로그램은 후방십자인대 재건술 후 이식물의 보호를 위해 12 주간 햄스트링 근육의 능동 수 축을 완전히 금지하고 있으므로 충분한 재활운동과 정 상 기능 회복을 위해 24 주로 기간을 설정하였다. 재활 운동 프로그램의 기간 별 참여 빈도는 후방십자인대 재 건술 직후부터 12 주 동안 병원에 방문하여 주 3 회 실시 하였고, 12 주 이후부터 24주까지는 주 2회 병원에 방 문하여 재활운동을 실시하였으며, 이 기간 가정 자가 재 활운동을 1 회 추가로 실시 할 수 있도록 교육 및 점검 을 시행하였다.

본 연구에서 적용한 재활운동 프로그램의 내용은 <Table 2>와 같다.

\begin{tabular}{|c|c|}
\hline Phases (week) & Specific exercises \\
\hline $\begin{array}{l}\text { Phase } 1 \\
(0 \sim 1 \text { week) }\end{array}$ & $\begin{array}{l}\text { Patellar mobilization } \\
\text { Partial weight shifting with support } \\
\text { Quadriceps setting }\end{array}$ \\
\hline $\begin{array}{l}\text { Phase } 2 \\
\text { (1 6 week) }\end{array}$ & $\begin{array}{l}\text { Continued Phase } 1 \text { exercise } \\
\text { Range of motion exercises (limited in } 90^{\circ} \text { ) } \\
\text {. Prone hang exercise with band (active assist) } \\
\text { CPM (continuous passive motion) exercise } \\
\quad \text { with BIODEX (passive) } \\
\text { Straight leg raises } 4 \text { directions with brace } \\
\text { Weight shifting squat limited in } 45^{\circ} \\
\text { Calf raises } \\
\text { Crutch gait exercise (full extension partial weight } \\
\quad \text { bearing) } \\
\text { Single balance exercise (stable) }\end{array}$ \\
\hline $\begin{array}{l}\text { Phase } 3 \\
\text { (6 12 week) }\end{array}$ & $\begin{array}{l}\text { Range of motion exercises (full range) } \\
\cdot \quad \text { Every position is possible (active assist \& } \\
\quad \text { passive) } \\
\text { Stationary bicycle } \\
\text { Straight leg raises } 4 \text { directions } \\
\text { Weight shifting squat limited in } 90^{\circ} \\
\text { Split squat } \\
\text { Step up / down lateral } \\
\text { Calf raises } \\
\text { Leg extension without weight } \\
\text { Normal gait exercise (full weight bearing) } \\
\text { Single balance exercise (unstable) }\end{array}$ \\
\hline $\begin{array}{l}\text { Phase } 4 \\
\text { (12 18 week) }\end{array}$ & $\begin{array}{l}\text { Single leg squat } \\
\text { Split squat } \\
\text { Lunge without weight } \\
\text { Step up / down } \\
\text { Calf raise exercise } \\
\text { Leg extension with weight }\left(0 \sim 60^{\circ}\right) \\
\text { Active hamstring curl exercise without weight } \\
\text { Normal gait exercise (full weight bearing) } \\
\text { Single balance exercise (unstable) } \\
\text { Jogging } \\
\text { Jumping in place }\end{array}$ \\
\hline $\begin{array}{l}\text { Phase } 5 \\
\text { (18 24 week) }\end{array}$ & $\begin{array}{l}\text { Single leg Squat (unstable) } \\
\text { Split squat } \\
\text { Lunge multiple directions with weight } \\
\text { Step up / down } \\
\text { Calf raise exercise } \\
\text { Leg extension with weight }\left(0 \sim 60^{\circ} \text { ) }\right. \\
\text { Active hamstring curl exercise with weight } \\
\text { Normal gait exercise (full weight bearing) } \\
\text { Single balance exercise (unstable) } \\
\text { T-Balance exercise } \\
\text { Running } \\
\text { Jumping in place } \\
\text { Speed training } \\
\text { Agility training } \\
\text { Quickness training }\end{array}$ \\
\hline
\end{tabular}

\section{4. 자료처리방법}

본 연구의 가설을 검정하기 위하여 독립 변인은 1) 측정 시기: 수술 전, 수술 후 12 주, 수술 후 24주와 2) 성 별: 남성, 여성으로 설정하였으며, 종속 변인으로 설정한 기능 회복은 하위 요인으로 주관적 기능 회복과 근력 회 
복으로 구성하였다. 측정 결과 분석을 위하여 통계 패키 지 프로그램 IBM SPSS 25.0을 활용하여 이원 반복 측 정 분산분석(two-way repeated measures ANOVA) 을 실시하였으며, 유의한 결과가 있는 변인에 대해서는 Bonferroni 사후 검증(post hoc)을 실시하였다. 통계적 유의 수준은 $a=0.05$ 로 설정하였다.

\section{결과}

\section{1. 주관적 기능의 변화}

후방십자인대 재건술 후 재활운동 프로그램 적용 에 따른 주관적 기능 변화 결과는 <Table3>와 같다. Lysholm 무릎 점수는 측정 시기에 따라 유의한 차이 가 나타나는 것으로 확인되었으나 $(\mathrm{p}<.001)$, 성별 집단 간 차이는 나타나지 않았다. 마찬가지로 IKDC 점수도
측정 시기에 따라 유의한 차이가 나타나는 것으로 확인 되었으나 $(\mathrm{p}<.05)$, 성별 집단 간 차이는 나타나지 않았 다. Lysholm 무를 점수와 IKDC 점수 모두 성별 집단 과 측정 시기 간의 상호작용 효과는 유의하지 않은 것 으로 확인하였다.

\section{2. 근력 기능의 변화}

근력의 변화를 살펴보기 위하여 $60 \% / \mathrm{sec}$ 에서 슬관절 신전 시와 굴곡 시에 체중 당 최대 우력(peak torque/ bodyweight) 값을 백분율 $(\%)$ 로 분석하였다. 후방십자 인대 재건술 후 재활운동 프로그램 적용에 따른 근력의 변화는<Table $4>$ 와 같다. 환측 슬관절 신전 시 단위 체 중 당 최대 우력 값은 성별 집단과 측정 시기에 따라 유 의한 차이가 나타났으나 $(\mathrm{p}<.01)$, 성별 집단과 측정 시 기 간의 상호작용 효과는 유의하지 않음을 확인하였다.

Table 3. Changes of subjective function

\begin{tabular}{|c|c|c|c|c|c|c|}
\hline Section & Group & Pre-Op & Post-Op 12wks & Post-Op 24wks & Significance & \\
\hline \multirow{3}{*}{ Lysholm } & Male & $60.64 \pm 15.74$ & $78.82 \pm 11.80$ & $76.00 \pm 11.04$ & Group & .713 \\
\hline & & & & & Period & $.000^{* * *}$ \\
\hline & Female & $63.00 \pm 13.50$ & $75.00 \pm 16.24$ & $82.36 \pm 10.70$ & GxP & .275 \\
\hline \multirow{3}{*}{ IKDC } & Male & $57.73 \pm 15.59$ & $62.64 \pm 9.28$ & $72.64 \pm 18.58$ & Group & .739 \\
\hline & & & & & Period & $.005^{* *}$ \\
\hline & Female & $58.55 \pm 15.58$ & $61.18 \pm 10.25$ & $69.27 \pm 11.14$ & GxP & .859 \\
\hline
\end{tabular}

Values are $\mathrm{M} \pm \mathrm{SD}$, Pre-Op: Previous-Operation, GxP : Group x Period, wks : weeks, ${ }^{*} \mathrm{P}<.05,{ }^{* *} \mathrm{P}<.01,{ }^{* * *} \mathrm{P}<.001$

Table 4. Comparison of isokinetic strength of knee joint $60 \% \mathrm{sec}$

\begin{tabular}{|c|c|c|c|c|c|c|c|}
\hline & Factor & Group & Pre-Op & Post-Op 12wks & Post-Op 24wks & Signific & \\
\hline \multirow{7}{*}{ In } & \multirow[t]{2}{*}{ Extension PT/BW\% } & Male & $200.18 \pm 69.33$ & $149.10 \pm 67.25$ & $196.00 \pm 76.38$ & $\begin{array}{l}\text { Group } \\
\text { Period }\end{array}$ & $\begin{array}{l}.003^{* *} \\
.001^{* *}\end{array}$ \\
\hline & & Female & $109.13 \pm 49.41$ & $88.00 \pm 37.41$ & $115.26 \pm 46.36$ & GxP & .230 \\
\hline & \multirow{2}{*}{ Flexion PT/BW\% } & Male & $105.75 \pm 40.42$ & $81.14 \pm 26.49$ & $113.44 \pm 30.83$ & $\begin{array}{l}\text { Group } \\
\text { Period }\end{array}$ & $\begin{array}{l}.001^{* *} \\
.001^{* *}\end{array}$ \\
\hline & & Female & $59.99 \pm 21.27$ & $53.87 \pm 24.17$ & $72.99 \pm 22.15$ & GxP & .262 \\
\hline & \multirow{3}{*}{ H/Q Ratio (\%) } & Male & $55.95 \pm 24.60$ & $60.40 \pm 29.85$ & $61.53 \pm 18.55$ & Group & .621 \\
\hline & & & & & & Period & .172 \\
\hline & & Female & $59.81 \pm 19.65$ & $63.32 \pm 25.02$ & $68.64 \pm 23.91$ & GxP & .844 \\
\hline \multirow{9}{*}{ Un } & \multirow{3}{*}{ Extension PT/BW\% } & Male & $256.20 \pm 60.66$ & $255.05 \pm 61.37$ & $253.25 \pm 70.85$ & Group & $.015^{*}$ \\
\hline & & & & & & Period & .142 \\
\hline & & Female & $175.09 \pm 50.23$ & $194.76 \pm 58.09$ & $207.78 \pm 43.90$ & GxP & .073 \\
\hline & \multirow{3}{*}{ Flexion PT/BW\% } & Male & $129.76 \pm 33.28$ & $133.96 \pm 39.94$ & $133.22 \pm 39.99$ & Group & $.001^{* *}$ \\
\hline & & & & & & Period & $.037^{*}$ \\
\hline & & Female & $76.24 \pm 18.61$ & $83.98 \pm 19.91$ & $93.86 \pm 23.29$ & GxP & .189 \\
\hline & \multirow{3}{*}{ H/Q Ratio (\%) } & Male & $51.98 \pm 12.63$ & $52.46 \pm 10.05$ & $55.21 \pm 11.14$ & Group & $.033^{*}$ \\
\hline & & & & & & Period & .317 \\
\hline & & Female & $44.46 \pm 6.83$ & $44.39 \pm 8.00$ & $45.57 \pm 7.51$ & GxP & .781 \\
\hline
\end{tabular}

Values are $\mathrm{M} \pm \mathrm{SD}$, In: Involved, Un: Uninvolved, PT/BW\%: peak torque/body weight\%, H/Q: Hamstrings/Quadriceps, Pre-Op: Previous-Operation, GxP : Group $x$ Period, wks : weeks, ${ }^{*} \mathrm{P}<.05,{ }^{* *} \mathrm{P}<.01,{ }^{* * *} \mathrm{P}<.001$ 
마찬가지로 환측 슬관절 굴곡 시에도 단위 체중 당 최 대 우력 값은 성별 집단과 측정 시기에 따라 유의한 차 이가 나타났으나 $(\mathrm{p}<.01)$, 성별 집단과 측정 시기 간의 상호작용 효과는 유의하지

않음을 확인하였다. 건측 무를 신전 시 단위 체중 당 최대 우력 값은 성별 집단 간에는 유의한 차이가 나타 났으나 $(\mathrm{p}<.05)$ 측정 시기에 따른 유의한 차이는 확인하 지 못하였다. 한편, 건측 무릎 굴곡 시 단위 체중 당 최 대 우력 값은 성별 집단 $(\mathrm{p}<.01)$ 과 측정 시기 $(\mathrm{p}<.05)$ 모 두 유의한 차이를 확인하였으나, 성별 집단과 측정 시 기 간의 상호작용 효과는 유의하지 않음을 확인하였다.

\section{논의}

\section{1. 주관적 기능 회복의 변화}

본 연구에서는 후방십자인대 재건술 후 실시한 재활 운동 프로그램은 모든 측정 시기에서 두 성별 모두 주관 적 기능 회복에 있어서 우상향 되는 결과를 나타냈으며, 이는 선행 연구 결과와 일치하는 것으로 확인하였다. 선 행 연구에서는 수술이 필요한 후방십자인대 손상의 대부 분은 수술 전에 비하여 수술 후 주관적 기능 차이가 나 타난다고 보고하였다[18]. 후방십자인대 재건술 후 29 개월간 추적 관찰한 결과 Lysholm 무릎 점수에 있어서 유의한 차이가 나타났다고 보고하였으며 [19], 후방십 자인대 재건술 후 2 년간 추적 관찰한 결과, $\mathrm{IKDC}$ 점수 에 있어서 유의한 차이가 나타났다고 보고하였다[20]. 또한 아킬레스 동종 건을 이용한 관절경적 후방십자인 대 재건술을 시행한 환자 군에 대하여 관절운동범위, Lysholm 무를 점수, IKDC 점수, 후방 전위 검사, 보행 검사를 분석한 결과 모든 임상적 결과가 통계학적으로 유의한 차이가 나타났다고 보고하였다[21]. Jung 등의 연구에서는 후방십자인대 손상 환자 234 명을 남성 53 명, 여성 181명 두 그룹으로 나누어 후방십자인대 재건 술 후 62 개월간 무릎의 안정성 회복을 추적 관찰한 결 과 $\mathrm{IKDC}$ 점수에서 두 그룹 모두 유의하게 증가하였음 을 확인하였다[12]. 후방십자인대 재건술 후 재활운동 프로그램이 주관적 기능에 있어 성별 간 차이가 나타나 지 않은 것은 두 그룹 모두 동일한 재활운동 프로그램 에 성실히 참여했고 측정 기간에 따라 근력이 유의한 수 준으로 향상했기 때문으로 생각되며, 이러한 결과는 선 행 연구와도 일치하는 결과임을 확인하였다[12]. 후방
십자인대 급성 손상과 재건술 후에 환자들은 상당 기간 일상 생활에 제약이 있고 불편감을 호소한다. 따라서 후 방십자인대 재건술 후 보행과 같은 일생 생활에 필요한 동작을 포함한 재활운동 프로그램의 참여가 환자의 불 편감 개선에 영향을 미쳤기 때문에 환자가 느끼는 주관 적 기능 회복에 긍정적인 효과가 나타났다고 생각한다.

\section{2. 근력의 변화}

본 연구에서는 후방십자인대 재건술 후 재활운동 프 로그램에 따른 근력 기능 회복을 평가한 결과 환측 근력 은 측정 시기와 성별 집단 간 유의한 차이를 나타내는 것 으로 확인하였다. 이러한 결과는 후방십자인대 재건술 후 임상적 결과와 운동 능력 회복을 평가하였을 때, 수 술 전에 비해 수술 후 호전된다는 선행 연구[22]와 일 치하는 결과를 나타낸다.

본 연구 결과 후방십자인대 재건술 후 재활운동 프 로그램이 H/Q Ratio(\%)에 미치는 영향이 유의한 수준 으로 확인되지는 않았으나, 측정 시기 별로 두 집단 모 두 우상향 되는 방향성을 확인할 수 있었다. Appen과 Duncan의 선행 연구에서는 대퇴사두근에 대한 슬괵근 의 정상적인 근력 비율 범위를 50-80\%로 보고 하였으 며[23], Nosse의 연구에서는 30-90\%로 보고하였다 [24]. 본 연구에서는 수술 전, 12 주 후, 24 주 후 H/Q $\operatorname{Ratio}(\%)$ 가 정상적인 수준임을 확인할 수 있다. 재활운 동 프로그램 중 슬괵근 능동적 수축 운동은 경대퇴관절 에 강한 후방 전단력을 주어 후방십자인대 이식물의 치 유에 방해가 된다는 연구[12]와 12주 이후부터 슬괵근 의 능동적 수축 운동 실시를 권장한다는 보고[25]에 따 라 수술 후 12 주까지는 슬괵근의 능동적 수축 운동을 제 한하고 있어 12 주 후에도 연속된 재활운동이 꼭 필요할 것으로 사료된다. Lee 등의 연구에서는 후방십자인대 재건술 후 카프레이즈, 레그 프레스, 미니 스쿼트 등의 적절한 체중 지지 운동이 근력 향상을 촉진시키고 대두 사두근과 슬괵근의 비율을 건측과 비슷한 수준으로 증 가시킨다고 하였으며 [20], 본 연구에서도 일치하는 결 과를 확인할 수 있었다.

본 연구 결과 남성이 상대적으로 여성 보다 후방십 자인대 재건술 전부터 양적으로 높은 근력 수준을 보이 고 있으며, 이는 측정 시기별로 동일한 양상을 나타내 고 있다. 후방십자인대 재건술 후 재활운동 프로그램이 성별 집단 간 근력에 유의한 차이가 나타난 배경은 성 
별 생리학적 특성 차이에 의한 결과로 생각되며 20 30 대 성인의 하지 등속성 근력 평가 기준치에 대한 연구 [26]에서도 본 연구와 일치하는 결과를 확인할 수 있었 다. 이에, 후방십자인대 재건술 후 두 성별 집단 모두 근 력 회복을 위하여 효과적인 재활운동 프로그램이 필요 함을 의미하며, 재활운동 프로그램 종류와 참여 방법, 빈도, 기간의 차이에 대한 연구가 필요할 것으로 생각되 며, 더 나아가서 일상 생활과 관련된 기능적 검사를 통 하여 재활운동 프로그램의 효과를 검증하는 연구가 필 요할 것으로 사료된다.

\section{3. 연구의 제한점}

본 연구의 제한점은 첫째, 본 연구의 실험 참여자 수 가 20 명으로 제한되어 본 연구 결과 만을 가지고 일반 화하기에는 부족하다. 둘째, 본 연구에서 대조 군으로 후방십자인대 재건술을 시행하지 않은 경우와 재활운동 프로그램을 진행하지 않은 경우를 설정하지 않았기 때 문에 온전한 재활운동 프로그램의 효과를 입증하기에 는 다소 부족함이 있다. 셋째, 본 연구에 참여한 대상자 모두 24 주간 재활운동 프로그램에 성실히 참여하였으 나, 수술 12 주 후부터는 참여자의 지속적인 참여를 위 해 병원 방문 재활운동을 주 2 회로 줄이고, 주 1 회는 사 전 교육 후 자가 운동으로 실시하여 실험을 완벽히 통 제하지 못했다.

\section{결론 및 제언}

후방십자인대 재건술 후 재활운동 프로그램에 따른 주관적 기능 회복은 성별 간의 차이가 나타나지 않았으 나 근력 회복은 성별 간 유의한 차이가 있는 것으로 나 타났다. 즉, 후방십자인대 재건술 후 재활운동 프로그 램은 두 성별 집단 모두 주관적 기능과 근력 기능 향상 에 효과적이다. 하지만 근력 회복에 대한 연구는 선행 연구가 매우 미미한 실정이며, 정상 기능 회복을 위한 재활운동 프로그램의 종류, 기간, 기능 검사 방법이 제 한적이기 때문에 구체적으로 규명할 필요성이 있다. 후 속 연구에서는 보다 많은 샘플을 확보하여, 대조 군과 의 비교를 통하여 재활운동 프로그램의 효과를 보다 실 증적으로 제시하고자 한다. 더 나아가서 일상생활이나 스포츠 활동에 사용되는 동작을 기반으로 한 보다 기능 적인 검사와 재활운동 프로그램에 대한 연구가 필요할 것으로 사료된다.

\section{Conflicts of Interest}

The authors declare no conflict of interest.

\section{Funding}

This research was supported by College of Culture \& Sports, Korea University Research Fund of 2021.

\section{References}

1. Fanelli GC, Edson CJ. Posterior cruciate ligament injuries in trauma patients: part II. Arthroscopy: The Journal of Arthroscopic \& Related Surgery. 1995;11(5):526-9.

2. Schulz M. Russe K Weiler A Eichhorn HJ Strobel MJ. Epidemiology of posterior cruciate ligament injuries Arch Orthop Trauma Surg. 2003;123(4):186-91.

3. Seo SS, Gwak HC. The Treatment of Combined Injury of Posterior Cruciate Ligament \& Medial Collateral Ligament: Result of Treatment (MCL Stability depends on PCL Status). Knee Surgery \& Related Research. 2002;14(2):186-92.

4. Wilk KE, Andrews JR, Clancy WG, Crockett HC, O’Mara JW. Rehabilitation programs for the PCL-injured and reconstructed knee. Journal of Sport Rehabilitation. 1999;8(4):333-61.

5. Logterman SL, Wydra FB, Frank RM. Posterior cruciate ligament: anatomy and biomechanics. Current reviews in musculoskeletal medicine. 2018;11(3):510-4.

6. Mariani PP, Becker R, Rihn J, Margheritini F. Surgical treatment of posterior cruciate ligament and posterolateral corner injuries. An anatomical, biomechanical and clinical review. The Knee. 2003;10(4):311-24.

7. Pache S, Aman ZS, Kennedy M, et al. Posterior cruciate ligament: current concepts review. Archives of Bone and Joint Surgery. 2018;6(1):8.

8. Irrgang JJ, Ho H, Harner CD, Fu FH. Use of the International Knee Documentation Committee guidelines to assess outcome following anterior cruciate ligament reconstruction. Knee Surgery, Sports Traumatology, Arthroscopy. 1998;6(2):107-14. 
9. Fanelli GC, Edson CJ. Arthroscopically assisted combined anterior and posterior cruciate ligament reconstruction in the multiple ligament injured knee: 2-to 10-year follow-up. Arthroscopy: The Journal of Arthroscopic \& Related Surgery. 2002;18(7):703-14.

10. Senese M, Greenberg E, Lawrence JT, Ganley T. Rehabilitation following isolated posterior cruciate ligament reconstruction: a literature review of published protocols. International journal of sports physical therapy. 2018;13(4):737-51.

11. Lee KW, Lee SH, Park JG, Kim HY, Kim BS, Choy WS. Functional Evaluation after Arthroscopic Reconstruction in Isolated and Combined Injury of Posterior Cruciate Ligament. Korean Arthroscopy Society. 2002;6(2):115-20.

12. Jung TM, Lubowicki A, Wienand A, Wagner M, Weiler A. Knee stability after posterior cruciate ligament reconstruction in female versus male patients: a prospective matched-group analysis. Arthroscopy: The Journal of Arthroscopic \& Related Surgery. 2011;27(3):399-403.

13. Jee YS. The Changes of Pain degree, Range of motion, and Musculo - articulation Functions in Athletes with Isolated Posterior Cruciate Ligament Injury. The Korean Alliance for Health,Physical Education. 2002;41(1):50115.

14. Kim JG, Lee YS, Yang BS, Oh SJ, Yang SJ. Rehabilitation after posterior cruciate ligament reconstruction: a review of the literature and theoretical support. Archives of orthopaedic and trauma surgery. 2013;133(12):168795.

15. Simhal RK, Bovich M, Bahrun EA, Dreese JC. Postoperative Rehabilitation of Posterior Cruciate Ligament Surgery: A Systematic Review. Sports medicine and arthroscopy review. 2021;29(2):81-7.

16. Lysholm J, Tegner Y. Knee injury rating scales. Acta orthopaedica. 2007;78(4):445-53.

17. Baltzopoulos V, Brodie D. Isokinetic dynamometry. Sports medicine. 1989;8(2):101-16.

18. Kim JG. Treatment of Posteolareral Rotatory Instability of the Knee. Journal of the Korean Arthroscopy Society. 2011;15(2):146-54.

19. Zayni R, Hager J-P, Archbold P, et al. Activity level recovery after arthroscopic PCL reconstruction: a series of 21 patients with a mean follow-up of 29 months. The Knee. 2011;18(6):392-5.

20. Lee DW, Jang HW, Lee YS, et al. Clinical, functional, and morphological evaluations of posterior cruciate ligament reconstruction with remnant preservation: minimum 2-year follow-up. The American journal of sports medicine. 2014;42(8):1822-31.

21. Chun CH, Cho J-D, Keun-ChurlChun. Gait Analysis After Posterior Cruciate Ligament Reconstruction Using Fresh-Frozen Achilles Allograft. Korean Orthopaedic Society for Sports Medicine. 2009;8(2):76-82.

22. Park JY, Chun CH, Yang JH, Woo YH. Clinical Article : Arthroscopic Double-Bundle Posterior Cruciate Ligament Reconstruction Using Split Achilles Allograft -Clinical Result and Recovery of Sports Activity. The Korean Journal of Sports Medicine. 2008;26(2):191-7.

23. Appen L, Duncan PW. Strength relationship of the knee musculature: effects of gravity and sport. Journal of Orthopaedic \& Sports Physical Therapy. 1986;7(5):2325.

24. Nosse LJ. Assessment of selected reports on the strength relationship of the knee musculature. Journal of Orthopaedic \& Sports Physical Therapy. 1982;4(2):7885.

25. Lynch AD, Chmielewski T, Bailey L, et al. Current concepts and controversies in rehabilitation after surgery for multiple ligament knee injury. Current reviews in musculoskeletal medicine. 2017;10(3):328-45.

26. Jin T-W, Sin H-J, Kim Y-W, Park S-T. Development of Low-extremity Isokinetic Strength Normative Database for Adults 20-30. Korean Academy of kinesiology. 2011;13(4):19-27. 